\title{
ORAL HYGIENE STATUS OF ADOLESCENTS IN A LOCAL GOVERNMENT AREA OF OYO STATE NIGERIA.
}

\author{
S.E. Ogunsile ${ }^{1}$ and I. $\mathrm{Ojo}^{2}$ \\ ${ }^{1}$ Department of Human Kinetics and Health Education, University of Ibadan, Nigeria. \\ ${ }^{2}$ Department of Dentistry, College of Medicine, University of Ibadan, Nigeria.
}

\begin{abstract}
Physical examination was carried out in the oral cavity of adolescents in Ibadan North LGA of Oyo State Nigeria in order to determine their oral hygiene status. The dental plaque score was used to classify the oral hygiene status of the adolescents, while the presence of holes in the teeth was used to indicate tooth decay. Six hundred and twenty one adolescents between the ages 11 and 19years, drawn from 10 schools located within Ibadan North LGA of Oyo State Nigeria, participated in the study. Oral hygiene status was fair in majority (74.6\%) of the adolescents. Percentage occurrence of tooth decay among the adolescents was $6.3 \%$ and this was found to be prevalent among: the females (69.2\%), those within ages 14 and 16 years (61.5\%) and those attending public schools (76.9\%). Significant gender, age and type of school difference $(p<0.05)$ existed in oral hygiene status of adolescents. Good oral hygiene status is capable of reducing tooth decay.
\end{abstract}

Keywords: Oral hygiene, oral hygiene status, adolescents, tooth decay

\section{INTRODUCTION}

Oral hygiene, a state in which the surfaces of all the teeth are plaque free (Loe, 2000), is highly important in the promotion of oral health. Oral health is part of total health and essential to quality of life (Petersen, 2008). It contributes to individual's wellbeing and quality of life by positively affecting physical and mental wellbeing, appearance and interpersonal relationships (Rao et al. 2005). Poor oral hygiene status often results in the accumulation of dental plaques which harbor bacteria that plays an important role in the etiology of dental caries, gingivitis and periodontitis. However, caries incidence could be prevented by efficient oral care ( Bratthal et al. 2006) and can be virtually eliminated by the regular meticulous professional removal of plaque (Mustahsen et al. 2008)

Periodontal disease and dental caries constitute major oral health problems in Nigeria with the prevalence being particularly high among young children and adolescents and the occurrence closely related to oral hygiene and socioeconomic class (Akpata, 2004). In a national study on periodontal status and treatment need among Nigerian children, prevalence of dental caries was as high as $30 \%$ and $43 \%$ among Nigerians aged 12 years and 15 years respectively 
82

\section{Ogunsile and Ojo}

(Adegbembo and El- Nadeef, 1995). AdekoyaSofowora et al. (2006) reported dental caries prevalence as high as $13.9 \%$ among 12-yearold suburban Nigerian schoolchildren with decayed teeth contributing majority of the DMFT index.

In view of the importance of good oral hygiene in maintaining good oral health of adolescents, it is often necessary to determine their oral hygiene status from time to time with the aim of discovering possible risk to oral health problems among them. This study thus aimed at assessing and describing the oral hygiene status of adolescents in Ibadan North (LGA) of Oyo State Nigeria.

\section{Sample}

The study sample $(n=621)$ was drawn from 10 schools located within Ibadan North Local Government Area of Oyo State, Nigeria. The schools, both Government and private owned, were selected using simple random sampling method. Each of the schools selected was divided into clusters, namely: junior secondary schools I, II and III and senior secondary schools I, II and III. Two clusters each (one junior and one senior) were selected randomly from each school. Thirty students from each cluster in the junior schools and forty from each cluster in the senior schools (making a total of seven hundred) were intended to form the study participants. However, only six hundred and twenty one students (88.7\%), two hundred and seventy three $(44 \%)$ males and three hundred and fourty eight $((66 \%)$ females were obtained for the oral examination. In addition, the ages of the subjects ranged from $11-19$ years.

\section{Instrument}

The instruments for collecting the data required for this study was oral examination. Prior to the examination, the selected schools were visited to seek the consent of the school authority and the students to be involved in the study. Only the students who gave their consent constituted the subjects for the study. The subjects had physical examination carried out in their oral cavity in order to determine their oral hygiene status and also to detect the presence of hole in the teeth. The examination was carried out in the students' classrooms with the students sitting in an upright position. Disposable items such as: spatulas, hand gloves and facemasks were used in the course of the examination and the source of light was natural light.

The dental plaque score ranging from 0 to 2 was used in this study to classify the oral hygiene status of the subjects. There were three classifications: poor (2), fair (1) and good (0). Subjects who had plaque covering more than one third (1/3) of the anterior teeth were scored ' 2 ' indicating poor oral hygiene status. Those having plaque visible on their teeth but not covering more than one third $(1 / 3)$ of the anterior teeth were scored ' 1 ' indicating fair oral hygiene status while those with no observable plaque were scored ' 0 ' indicating good oral hygiene status. In addition to the oral examination, demographic attributes of the respondents such as age, gender and type of school were also noted. Eight trained final year dental students who had earlier been involved in a related field work organized by Dental School, College of Medicine, University of Ibadan, Nigeria were the research assistants for this study. The research was carried out between January and June 2006.

\section{Statistical Analysis}

Data obtained were analysed using SPSS 11.0 for windows. Subjects were first categorized into either having poor (2), or fair (1) or good (0) oral hygiene status based on the extent of plaque accumulation on the exposed surfaces of the teeth. Frequency counts and percentages of each category were then obtained.

Chi square test was carried out to determine whether significant difference in oral hygiene status existed among adolescents based on their age, school type and gender. In addition, frequency counts and percentages of subjects with holes in their teeth were determined. All differences were considered significant at $\mathrm{p}<0.05$. 
This study was approved by the research review committee of the Department of Human Kinetics and Health Education, Faculty of Education, University of Ibadan Nigeria and the Executive members of the Dental Students' Association, Dental School, University College Hospital Ibadan, Nigeria.

\section{RESULTS}

The findings of this study are represented in the tables below:

Table 1: Distribution of Subjects by Gender, Age Group and Type of School and Dental Caries Occurrence

\begin{tabular}{lcc}
\hline Item & Quantity & Percentage (\%) \\
\hline Total & 621 & 100.0 \\
Gender & & \\
Male & 273 & 44.0 \\
Female & 348 & 44.0 \\
Age group & & \\
(years) & & \\
$11-13$ & 146 & 23.5 \\
14-16 & 388 & 62.5 \\
17-19 & 87 & 14.0 \\
School type & & \\
Public & 488 & 78.6 \\
Private & 133 & 21.4 \\
Dental caries & & 6.3 \\
Existing & 39 & 93.7 \\
Not existing & 582 & \\
\hline & & \\
\hline
\end{tabular}

Table 1 shows the demographic distribution of subjects used in this study. Over 50\% were females, nearly two-third was between 14-16 years, those attending public schools were $79 \%$ and less than $10 \%$ had dental caries.
Table 2 shows the result of the data analysis on subjects' oral hygiene status. Dental plaque score was 'fair' in majority $(74.6 \%)$ of the adolescents. Poor oral hygiene status was observed more among: the male subject $(65.9 \%)$, those within the age group 14-16 years $(51.2 \%)$ and those attending public schools $(95.1 \%)$. Significant gender, age group and type of school difference in oral hygiene status was observed.

Table 3 shows that more female $(69.2 \%)$ than male $(30.8 \%)$, those within age group 1416years $(61.6 \%)$ and those attending public schools $(76.9 \%)$ had the highest rate of tooth decay occurrence.

Table 4 shows that significant relationship existed between oral hygiene status of subjects and tooth decay occurrence. Subjects with good oral hygiene status had lesser occurrence of dental caries than those classified as having poor and fair oral hygiene status.

\section{DISCUSSION}

The findings of this study revealed a fairly good oral hygiene status among majority of the adolescents involved in this study. This is likely the reason for a low percentage occurrence of tooth decay among them. Occurrence of tooth decay was found to be significantly correlated with adolescents' oral hygiene status. Good oral hygiene status was associated with reduced occurrence of tooth decay in this study. This association confirms the assertions of oral health experts like Ostberg et al. (1999) and Pauraite (2003) that improved and efficient oral hygiene is highly essential in the decline of dental caries. It is however pertinent to note that although dental caries was not evident in most of the subjects as at the time of this study, majority $(74.6 \%)$ of them had about one third $(1 / 3)$ of their exposed teeth surface covered by plaque indicating fair oral hygiene status. Oral health information needs to continually be communicated to these adolescents in order to improve their oral hygiene status and prevent dental problems 
84 Ogunsile and Ojo

Table 2: Distribution of Subject base on dental plaque Score

\begin{tabular}{lccccc}
\hline Item & Poor $(\%)$ & Fair $(\%)$ & Good $(\%)$ & Total $(\%)$ & $\begin{array}{c}\text { P } \\
\text { value }\end{array}$ \\
\hline Value & $41(6.6)$ & $463(74.6)$ & $117(18.8)$ & $621(100.0)$ & \\
Gender & & & & \\
Male & $27(65.9)$ & $199(43.0)$ & $47(67.1)$ & $273(44.0)$ & 0.027 \\
Female & $14(34.1)$ & $264(57.0)$ & $70(32.9)$ & $348(66.0)$ & \\
& & & & \\
Age group & $10(24.4)$ & $95(20.5)$ & $41(35.0)$ & $146(23.5)$ & 0.008 \\
$11-13$ years & $21(51.2)$ & $302(65.2)$ & $65(55.6)$ & $388(62.5)$ & \\
$14-16$ years & $10(24.4)$ & $66(14.3)$ & $11(9.4)$ & $87(14.0)$ & \\
$17-19$ years & & & & & \\
School type & $39(95.1)$ & $363(78.4)$ & $86(73.5)$ & $488(78.6)$ & 0.011 \\
$\begin{array}{l}\text { Public } \\
\text { Private }\end{array}$ & $2(4.9)$ & $100(21.6)$ & $31(26.5)$ & $133(21.4)$ & \\
\hline
\end{tabular}

Table 3: Distribution of Subjects base on

Tooth Decay Occurrence

\begin{tabular}{lcc}
\hline Item & Tooth decay & Percentage (\%) \\
\hline Total & 39 & 100.0 \\
Gender & & \\
Male & 12 & 30.8 \\
Female & 27 & 69.2 \\
Age group & & \\
(years) & & \\
$11-13$ & 10 & 25.6 \\
$14-16$ & 24 & 61.6 \\
17-19 & 5 & 12.8 \\
School type & & \\
Public & 30 & 23.1 \\
Private & 9 & \\
\hline
\end{tabular}

Significant gender difference in oral hygiene status was observed in this study. More females than male had poor oral hygiene status and
Table 4: Oral Hygiene Status and Tooth Decay among Adolescents

\begin{tabular}{lllll}
\hline & & Tooth & Decay & \\
$\begin{array}{l}\text { Oral } \\
\text { hygiene } \\
\text { status }\end{array}$ & & Yes & No & Total \\
\hline Good & Count & 4.0 & 108.0 & 112 \\
& Expected & 7.4 & 104.6 & 112 \\
& & & & \\
Fair & Count & 29.0 & 411.0 & 440 \\
& Expected & 29.1 & 410.9 & 440 \\
& & & & \\
Poor & Count & 39.0 & 551.0 & 590 \\
& Expected & 39.0 & 551.0 & 590 \\
\hline
\end{tabular}

tooth decay occurrence. This is similar to the findings of previous studies. Addo-Yobbo et al. (1991), Rai et al. (2007), Barmes (1999) and 
Blay et al. (2000) all reported from their findings that females are seriously more affected by dental caries than their male counterparts. The likely reason for this finding is that girls tend to appreciate sugary foods and snacking than boys. Health education programs to discourage these adolescents from excessive consumption of sweets and sugary foods should be carried out in order to prevent dental problems among them.

Students attending private schools had better oral hygiene status and lower occurrence of dental caries than their counterparts in public schools. This is similar to the finding of Hoffman et al. 2004. Students attending private schools are often from high social class and hence often concerned about their personality. Schools, whether private or public, should make all efforts to constantly disseminate oral health information to their students so as to ensure good oral hygiene status among them.

The finding of this research supports the claim of Lewis and Ismail 1995 that one of the peaks for dental caries experience is 14 years. In this study, subjects within the age range 14-16 years had the highest caries rate (61.6).

\section{CONCLUSION}

The findings of this research confirm the fact that there is a close association between oral hygiene status and tooth decay. The low percentage occurrence of tooth decay (6.3\%) among these adolescents was closely associated with the fact that majority of the adolescents $(93.4 \%)$ had at least moderate oral hygiene status. It can thus be concluded that 'A clean tooth never decays' hence to maintain the natural dentition throughout life, regular removal of dental plaque is essential. Good oral hygiene habits must be practiced thoroughly on a daily basis. This can thus be used to encourage parents to ensure that their children brush twice daily i.e. morning and night so that they will not suffer from tooth decay early in life (American Academy of Pediatric Dentistry, 2010).
Oral H ygiene Status of Adolescents ...

\section{ACKNOWLEDGEMENT}

The authors of this work wish to sincerely appreciate the students who constituted the subjects of this study, the authorities of the schools involved and the Dental Students' Association, Dental School, University College Hospital, Ibadan, Nigeria.

\section{REFERENCES}

American Academy of Pediatric Dentistry (2010). "Guideline on caries risk assessment and management in infants, children and adolescents". Pediatric Dental Journal 32 (special edition)

Adekoya-Sofowora, C. A., Nasir, W. O., Oginni, A. O. and Taiwo, M. (2006). "Dental caries in 12-years old suburban Nigerian school children". Africa Health Science 6: $145-150$

Adegbembo, A. O. and El - Nadeef, M. A. I. (1995). "National study of periodontal status and treatment need among Nigerians". International Dental Journal 45: $197-203$

Addo-Yobbo, C., Williams, S.A. and Curzon, M. E. J. (1991). "Dental caries experience in Ghana among 12years old urban and rural school children". Caries Research 25: $311-314$

Akpata, E. S. (2004). "Oral health in Nigeria". International Dental Journal 53: 361-365

Barmes, D. E. (1999). "A global view of oral diseases today and tomorrow". Community Dentistry and Oral Epidemiology 27: $2-7$

Blay, D., Astrom, A. N. and Haugejorden, O. (2000). "Oral hygiene and sugar consumption among urban and rural adolescents in Ghana", Community Dentistry and Oral Epidemiology 28: 443-450

Bratthal, D., Petersen, P. E., Ramanathan, S. 
and Jackson, B. (2006). "Oral and Craniofacial diseases and disorders" In: Jamison, D.T., Breman, J.G., Measham, A.R., Alleyne, G., Claeson, M., Evans, D.B., Jha, P., Mills, A. and Musgrove, P. (Editors) Disease Control Priorities in Developing Countries $2^{\text {nd }}$ edition. World Bank, Washington DC

Campus,G., Cagetti, M. G., Senna, A., Spano, G., Benedicenta, S. and Sacco, G. (2009). "Differences in oral health among Italian adolescents related to the type of school attended". Oral Health Preventive Dentistry 7: 323-30

Hoffmann, R. H. S., Cypriano, S., Sousa, M.LR. and Wada, R.S. (2004). "Dental caries experience base on school type”. Cardenos Saúde Pública 20: 552528

Lewis, D. W. and Ismail, A. I. (1995). "Prevention_of dental caries". Canadian Medical Association Journal 152: 12-22

Loe, H. (2000). "Oral hygiene in the prevention of caries and periodontal disease". International Dental Journal 50: 129-139

Mustahsen Ur Rehman, M., Mahmood, N. and Ur Rehman, B. (2008). "The relationship of caries with oral hygiene status and extra- oral risk factors". J Ayub Med Coll Abbottabad 20: 103-108
Ostberg, A. L., Halling, A. and Lindbald, U. (1999). "Gender differences in knowledge, attitude, behavior and perceived oral health among adolescents". Taylor and Francis group article 57: 231-236

Pauraite, J., Milciuviene, S., and Sakalauskiene, J. (2003). "The prevalence of gingivitis among 4-16 years old school children in Kaunas". Stomatologija Baltic Dental and Maxillofacial Journal 5: 97-100

Petersen, P. E. and Esheng, Z. (1998). "Dental caries and oral health behavior situation of children, mothers and schoolteachers in Wuhan People's Republic of China". International Dental Journal 48: 210-216

Petersen, P. E. (2003). "Continuous improvement of oral health in the $21^{\text {st }}$ century. The approach of the WHO global oral health program". Community Dentistry and Oral Epidemiology 31:3-24

Rao, D., Amitha, H. and Munshi, A. K. (2005). "Oral hygiene status of disabled children and adolescents attending special schools of South Canara, India". Honk Kong Dental Journal 2:107-110

Rai, B., Jain, R., Jigyasa, D., and Anand, S. C. (2007). Relationship between dental caries and oral hygiene status of 8 to 12 years old school children. The Internet Journal of Epidemiology 4 : 1-8 